\title{
Nonviral Delivery of Basic Fibroblast Growth Factor Gene to Bone Marrow Stromal Cells
}

\author{
Başak Açan Clements PhD, Charlie Y. M. Hsu BSc, Cezary Kucharski DVM, \\ Xiaoyue Lin MD, Laura Rose BSc, Hasan Uludağ PhD
}

Published online: 4 June 2009

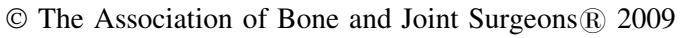

\begin{abstract}
Basic fibroblast growth factor (bFGF) is capable of stimulating osteogenic differentiation of preosteoblast cells in vitro and new bone tissue deposition in vivo. Delivering the gene for the protein, rather than the protein itself, is considered advantageous for bone repair since gene delivery obviates the need to produce the protein in pharmaceutical quantities. To explore the feasibility of bFGF gene delivery by nonviral methods, we transfected primary rat bone marrow stromal cells (BMSC) using cationic polymers (polyethylenimine and poly(L-lysine)-palmitic acid) in vitro. After delivering a bFGF-expression plasmid (pFGF2-IRES-AcGFP) to BMSC, the presence of bFGF in culture supernatants was detected by a commercial ELISA. As much as $0.3 \mathrm{ng} \mathrm{bFGF} / 10^{6}$ cells/day was obtained from the BMSC under optimal conditions. This secretion rate was $\sim 100$-fold lower than the secretion obtained from
\end{abstract}

One or more of the authors has received funding from the Canadian Institute of Health Research (CIHR) and Natural Sciences and Engineering Council of Canada (NSERC) (HU); CIHR Rx\&D scholarship (BAC); and CIHR Team Grant on Stem Cells for Skeletal Repair scholarship (CMYH) (PA: D. Rancourt, U. of Calgary). Equipment support was provided by the Alberta Heritage Foundation for Medical Research (AHFMR).

B. A. Clements, H. Uludağ

Faculty of Pharmacy and Pharmaceutical Sciences,

University of Alberta, Edmonton, Alberta, Canada

C. Y. M. Hsu, L. Rose, H. Uludağ

Department of Biomedical Engineering, Faculty of Medicine,

University of Alberta, Edmonton, Alberta, Canada

B. A. Clements, C. Kucharski, X. Lin, H. Uludağ ( $₫)$

\#830, Chemical and Materials Engineering Department,

Faculty of Engineering, University of Alberta, Edmonton,

Alberta T6G 2G6, Canada

e-mail: hasan.uludag@ualberta.ca immortal, and easy-to-transfect, human 293T cells. These data suggest the feasibility of modifying BMSC with nonviral delivery systems for bFGF expression, but also highlight the need for substantial improvement in transfection rate for an effective therapy.

\section{Introduction}

When inherent regenerative capacity is insufficient to repair a bone defect, agents capable of stimulating new bone deposition can be used to support wound healing. Cytokines that can simulate proliferation and morphogenesis of bone-depositing cells are gaining increased acceptance for this purpose $[2,17]$. The stimulatory cytokines are obviating the need for autografting and eliminating the morbidity associated with the autograft surgery. Cytokines are currently delivered after producing the proteins in pharmacological quantities by recombinant means. An alternative to recombinant protein delivery is gene delivery [20], where the gene of a therapeutic cytokine is delivered into a repair site. This approach eliminates the need to produce the proteins in large quantities, potentially minimizing the cost of the therapy. Cytokine gene delivery can be achieved by host cells that are modified ex vivo before administration to a repair site. Such an approach better mimics the embryonic bone development and is more likely to lead to a physiological tissue over time with relatively fewer adverse effects on local tissues.

Modification of host cells with nonviral methods is the preferred gene delivery approach due to safety concerns associated with viral methods (eg, immunogenicity, oncogenicity, etc) $[13,27]$. To this end, we have been developing nonviral carriers for modification of clinically relevant bone marrow stromal cells (BMSC) ex vivo [1, 8]. 
These experiments demonstrate modification of BMSC with a reporter gene encoding for green fluorescent protein (GFP). Investigating and optimizing GFP expression has been useful to understand various factors controlling transfection efficiency and, in particular, to design carriers with superior DNA delivery efficiency [1]. GFP, however, is a reporter protein, has no therapeutic potential and, hence, its expression cannot be used to predict clinical utility of nonviral delivery systems.

bFGF (also known as FGF-2) is a cytokine that increases proliferation and migration of osteoprogenitor cells and leads to enhanced healing when administered as a protein into a wound site $[19,25,28]$. bFGF is abundant in the extracellular matrix and it is detected in early fracture repair. bFGF is expressed by mesenchymal stem cells, maturing chondrocytes and osteoblasts, and has a role in endochondral bone formation [7]. Limited attempts have been made for bFGF delivery in bone repair, where one study used virally modified hematopoietic cells for bFGF delivery [14], one study used liposomal carriers for BMSC modification [12], and one study directly implanted a bFGF-expression vector (plasmid) with a collagen sponge [32]. Beneficial effects, such as increased angiogenesis and bone deposition, were observed with nonviral bFGF delivery [11,32], but in vitro bFGF secretion rates were determined in only one of these studies [14]. This is an important deficiency since precise knowledge of bFGF secretion rates is vital for realistic assessment of bFGF gene therapy.

We explored the feasibility of bFGF expression in primary rat BMSC. We first determined the response of the BMSC to bFGF protein treatment by assessing changes in the ALP activity as a result of bFGF treatment, a response well-characterized previously. Next, we treated BMSC with nonviral plasmid/polymer complexes to determine whether a desired ALP response could be achieved by using gene delivery rather than protein delivery. We then directly quantified the bFGF secretion from the modified cells in order to determine if a substantial amount of bFGF concentration was secreted into the culture medium. Finally, we determined the bFGF production from the robust (ie, easy-to-transfect) human 293T cells to obtain a relative measure of bFGF secretion between the 293T cells and BMSC.

\section{Materials and Methods}

This pilot study was designed to investigate bFGF production in primary BMSC by using nonviral gene delivery. The osteogenic differentiation of BMSC (based on ALP activity) was first determined by delivering bFGF protein or a bFGF expression system in the form of a plasmid. The bFGF secretion into the cell culture medium was then determined as a direct measure of bFGF expression. The bFGF secretion from BMSC was compared to secretion from the robust (ie, easy-to-transfect) human 293T cells to obtain a comparative measure of bFGF expression in both cellular systems (Fig. 1).

Dexamethasone, $\beta$-glycerol phosphate ( $\beta$-GP), ascorbic acid, p-nitrophenol phosphate (p-NPP), Hanks' balanced salt solution (HBSS), branched polyethylenimine (PEI, $25 \mathrm{kDa}$ ), protease inhibitor cocktail, and trypsin/EDTA were obtained from Sigma (St. Louis, MO). DMEM (high glucose with L-glutamine), penicillin $(10,000 \mathrm{U} / \mathrm{mL})$, and streptomycin $(10,000 \mu \mathrm{g} / \mathrm{mL})$ and OPTIMEM (oMEM) medium were from Invitrogen (Carlsbad, CA). Fetal bovine serum (FBS) was from Atlanta Biologicals (Lawrenceville, GA). An osteogenic medium (OM) was prepared by adding $3 \mathrm{mM} \beta$-GP and $30 \mathrm{nM}$ dexamethasone to a basic medium
Fig. 1 The experimental design employed in this study is summarized. The study groups for each experiment are indicated as well as the corresponding figures.

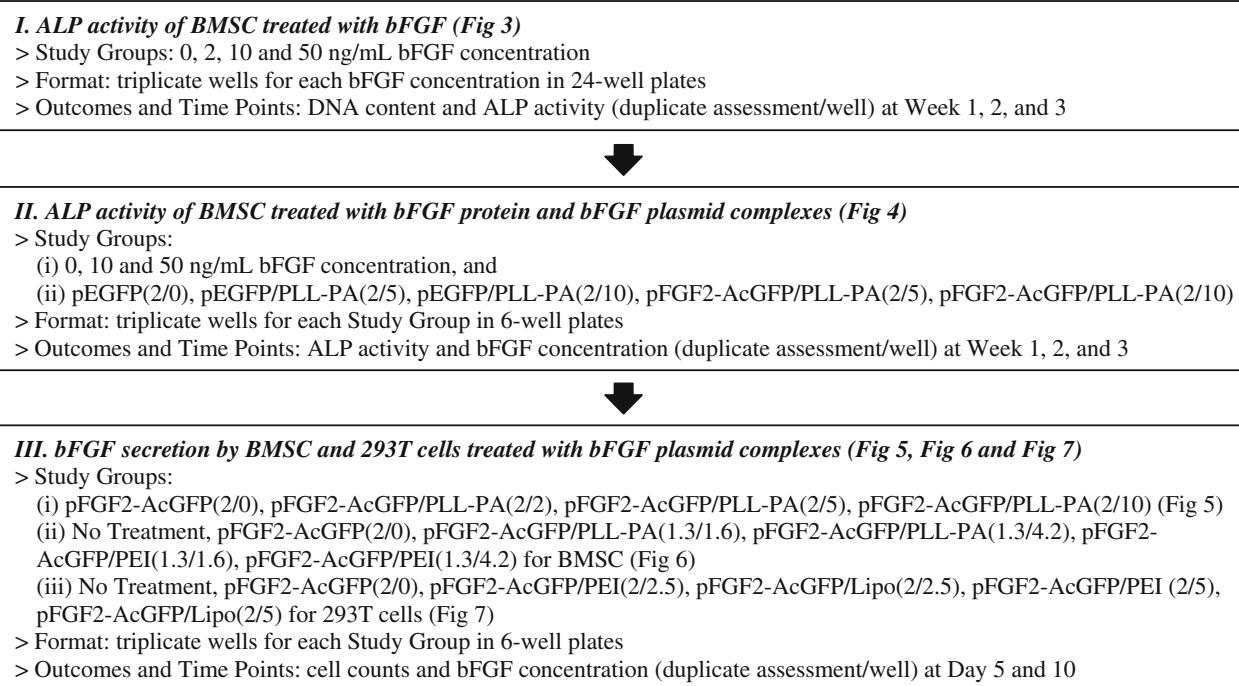


(BM: DMEM with $10 \% \mathrm{FBS}, 50 \mathrm{mg} / \mathrm{L}$ ascorbic acid, $100 \mathrm{U} / \mathrm{mL}$ penicillin and $100 \mu \mathrm{g} / \mathrm{mL}$ of streptomycin). Recombinant human bFGF was obtained from Peprotech Inc (Rocky Hill, NJ). CyQUANT kit for determination of DNA content was from Molecular Probes (Portland, OR). PLL-PA and control plasmid pEGFP-N2 were prepared as described previously [1, 16]. DuoSet ELISA kit for bFGF was from R\&D Systems (Minneapolis, MN). The 465 bp cDNA sequence encoding the $18 \mathrm{kDa}$ isoform of the human bFGF (NM_002006) was synthesized by IDT Technology (Coralville, IA) and cloned into the BglII/ EcoRI site of the mammalian expression vector pIRES2AcGFP1 (Clontech, Palo Alto, CA), which has an internal ribosomal entry site (IRES), a cytomegalovirus promoter/ enhancer, and a green fluorescence protein from Aequorea coerulescens (AcGFP). The resulting vector, hereon referred to as pFGF2-IRES-AcGFP, has a molecular weight of 5764 bp (Fig. 2). The isolation and culture of rat BMSC (passage 2-4) was previously described [31].

The BMSC were seeded in three 24-well plates for treatment with bFGF protein and the $\mathrm{BM}$ in the plates was replaced with OM after the cells reached $\sim 60 \%$ confluence. bFGF was added to OM to give a final concentration of $0,2,10$, and $50 \mathrm{ng} / \mathrm{mL}$ in triplicate [31]. Of the three plates, one was processed on weeks 1, 2, and 3. For studies lasting longer than 1 week, OM containing bFGF was removed, the cells were washed twice with HBSS, and supplemented with fresh OM containing the indicated concentrations of bFGF. A subsequent study repeated this study design with bFGF concentrations of 0,10 , and $50 \mathrm{ng} /$ $\mathrm{mL}$.

The BMSC were seeded in six-well plates treatment with the pFGF2-IRES-AcGFP plasmid. At $\sim 60 \%$ confluence, BM was replaced with oMEM containing $1 \% \mathrm{FBS}$, and DNA/polymer complexes (prepared at the ratios indicated in legends) were added to the cells in triplicate. The complexes were formed by combining the plasmid

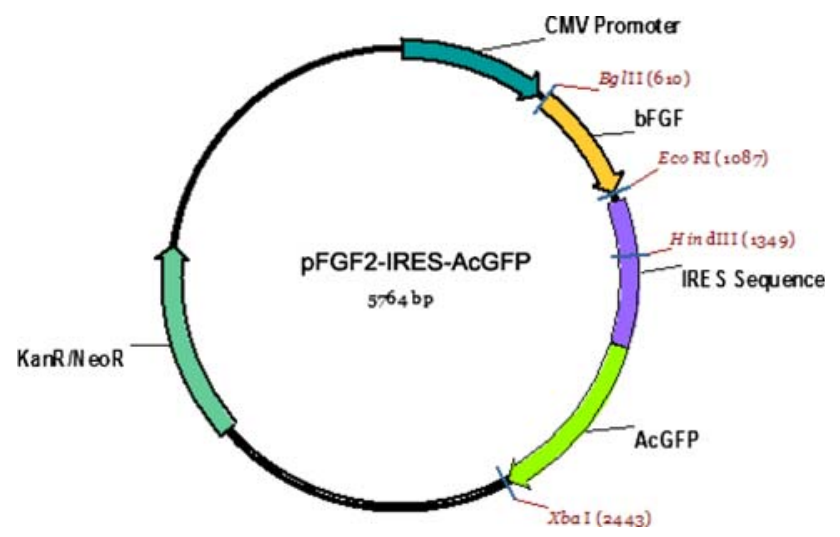

Fig. 2 The structure of pFGF2-IRES-AcGFP plasmid DNA vector used in this study is pictured.
(0.4 mg/mL pFGF2-IRES-AcGFP in $\mathrm{H}_{2} \mathrm{O}$ ) with PLL-PA or PEI $\left(1 \mathrm{mg} / \mathrm{mL}\right.$ in $\left.\mathrm{H}_{2} \mathrm{O}\right)$ in $150 \mathrm{mM} \mathrm{NaCl}$ to give a final volume of $150 \mu \mathrm{L}$. Where indicated, a control plasmid (pEGFP without a functional bFGF gene) was used as a control transfection. After mixing, the complexes were incubated at room temperature for 30 minutes, and added to cells in multiwell plates $(50 \mu \mathrm{L} /$ well in triplicate; $1 \mathrm{~mL}$ culture medium). The final plasmid and polymer concentrations are provided in figure legends. The cells were incubated with the complexes for 24 hours, and then washed with HBSS $(\times 2)$ and supplemented with either OM for experiments exploring osteogenic differentiation, or $\mathrm{BM}$ for experiments exploring the protein secretion. In the case of protein secretion, the culture supernatants were collected after 5 days and frozen until analysis for bFGF. Where indicated, cell numbers were determined by a hemocytometer to obtain a measure of polymer toxicities and specific bFGF secretion rate.

The transfection procedure used for BMSC modification was repeated in human 293 T cells. The latter cells have been readily modified in our hands with polymeric carriers [16]. Even though they have no clinical utility, bFGF secretion from $293 \mathrm{~T}$ cells served as a positive reference to bFGF production from the BMSC. The carriers used included PEI and the commercial transfection reagent Lipofectamine $^{\mathrm{TM}} 2000$.

The ALP activity of BMSC was investigated after treating the cells with either bFGF protein or pFGF2-IRESAcGFP/polymer complexes. ALP activity was investigated over 3 weeks, except gene delivery samples on Week 1 were not analyzed due to high cytotoxicity of the treatment after which the cell viability was recovered on weeks 2 and 3. To determine ALP activity, BMSC in 24-well plates were washed with HBSS $(\times 2)$ at predetermined time points and lysed with $400 \mu \mathrm{L}$ ALP buffer (0.5 M 2-amino-2methylpropan-1-ol and $0.1 \%$ (v/v) Triton-X; $\mathrm{pH}, 10.5)$ in the multiwell plates. After 2 hours, $150 \mu \mathrm{L}$ of lysed solutions (the remaining solution frozen) was transferred into the 48 -well plates, and $150 \mu \mathrm{L}$ of $2 \mathrm{mg} / \mathrm{mL}$ ALP substrate (p-NPP) was added to the cell lysate. The changes in optical density $\left(\lambda_{\mathrm{abs}}=405 \mathrm{~nm}\right)$ were immediately determined in the multiwell plate reader at periodic intervals for up to 15 minutes. The rate of change of absorbance (mAbs/ min) was normalized with the protein content of each sample (determined by the DC Protein Assay; Bio-Rad) to obtain a specific ALP activity (mAbs/min/ng protein).

The CyQUANT (Molecular Probes) assay kit was used for determination of DNA content in cell lysates. Manufacturers' suggested protocols were followed for assay conditions and fluorescence was measured with a plate reader $\left(\lambda_{\mathrm{abs}}=480 \mathrm{~nm}, \lambda_{\mathrm{em}}=527 \mathrm{~nm}\right)$. A DNA standard provided by the CyQUANT kit was used to estimate the DNA concentrations. 
The enzyme-linked immunosorbent assay (ELISA) for bFGF was performed on cell supernatants collected at predetermined time points (frozen at $-80^{\circ} \mathrm{C}$ until analysis), as well as on cell lysates. For cell lysis, BMSC in six-well tissue culture plates were washed with HBSS $(\times 2)$ and detached with trypsin/EDTA. After the addition of basic medium to stop trypsin action, cell suspensions were transferred into tubes, centrifuged at $600 \mathrm{rpm}$ for $6 \mathrm{~min}$ utes, and washed again with HBSS. An $80-\mu \mathrm{L}$ lysis buffer/ $10 \mu \mathrm{L}$ protease inhibitor solution was then added in each tube, vortexed, and then incubated on a shaker for 30 minutes. Resulting cell lysates were frozen at $-80^{\circ} \mathrm{C}$ until analysis. For ELISA, 96-well microplates were treated with the assay reagents as described in the manufacturer's protocol. The final absorbance values obtained was converted into a bFGF concentration $(\mathrm{ng} / \mathrm{mL})$ by using the standard curve obtained with the assay kit.

The data are summarized as the mean \pm standard deviation of triplicate measurements. The F-test was first employed to check for the equality of variances between comparison groups, by assuming a statistical difference of $\mathrm{p}<0.05$. The appropriate (ie, with equal or unequal variances; see Results) unpaired student's t test was undertaken to assess differences in the following outcome parameters: (1) the specific ALP activity among the BMSC groups treated with different bFGF protein concentrations or bFGF plasmid/polymer complexes; (2) bFGF protein concentration in the supernatants of BMSC groups treated with different bFGF plasmid/polymer complexes; and (3) bFGF concentration in the supernatants of 293T cell groups treated with different bFGF plasmid/polymer complexes.

\section{Results}

The bFGF treatment resulted in a reduction of DNA content (Week 1) and ALP activity (Weeks 1 to 3 ) in BMSC. Over the 3-week study period, there was an increase in
DNA content from Week 1 to Week 2, but not afterwards (Fig. 3A). No differences were observed among different treatment groups on weeks 2 and 3, however on Week 1 the cells treated with the highest dose of bFGF had the lowest DNA content ( $p \sim 0.002$ compared to untreated cells), suggesting an inhibition of cell growth at this dose, while the cells treated with 2 and $10 \mathrm{ng} / \mathrm{mL}$ bFGF had higher DNA contents when compared to untreated cells ( $p \sim 0.007$ ). The specific ALP activity increased gradually in BMSC in the absence of growth factor (Fig. 3B). The ALP activity was suppressed in the presence of 2,10 , or $50 \mathrm{ng} / \mathrm{mL}$ bFGF on Week $2(\mathrm{p}<7 \mathrm{E}-5)$ and in 10 and $50 \mathrm{ng} / \mathrm{mL}$ bFGF on Week 3 ( $\mathrm{p} \sim 0.02$ ).

Unlike the bFGF protein delivery, the delivery of bFGF gene in the form of plasmid complexes did not result in a reduction of ALP activity. For protein delivery (Fig. 4A), as in the previous study, ALP activity increased from Week 1 to Week 3 in the absence of bFGF and it was suppressed in the presence of 10 and $50 \mathrm{ng} / \mathrm{mL}$ bFGF. However, changes in ALP activity with gene delivery were more ambiguous (Fig. 4B). There was no increase in ALP activity over time, and gene delivery with pFGF2-IRESAcGFP/polymer complexes yielded equal or lower ALP values than those of gene delivery with plasmid DNA only, indicating no clear bFGF effect.

The amount of bFGF was detectable in the supernatants of BMSC after direct ELISA assessment. There were low amounts $(<0.01 \mathrm{ng} / \mathrm{mL})$ of bFGF in the supernatant of BMSC treated with plasmid alone $(2 / 0 \mu \mathrm{g} / \mathrm{mL}$ plasmid/ polymer) and plasmid with low concentration of PLL-PA (2/ $2 \mu \mathrm{g} / \mathrm{mL}$ plasmid/polymer) (Fig. 5). Higher levels of bFGF were detected for BMSC treated with complexes at $5 \mu \mathrm{g} / \mathrm{mL}$ PLL-PA $(2 / 5 \mu \mathrm{g} / \mathrm{mL}$ plasmid/polymer; $\mathrm{p} \sim 0.0002$ compared to control, $\mathrm{t}$ test with unequal variances). The highest bFGF concentration was $\sim 0.08 \mathrm{ng} / \mathrm{mL}$, lower than effective bFGF concentrations ( $\sim 2 \mathrm{ng} / \mathrm{mL}$ ) required for ALP reduction. In a followup study, where BMSC were transfected with polymers at lower plasmid and polymer concentrations, the
Fig. 3A-B Changes in (A) DNA content and (B) normalized ALP activity of BMSC after 1, 2, and 3 weeks of continuous bFGF treatment in OM. The medium was replaced with fresh OM with or without bFGF on a weekly basis. A reduction in ALP activity was evident for $50 \mathrm{ng} / \mathrm{mL}$ bFGF at Week 1, for all concentrations in Week 2, and for 50 and $10 \mathrm{ng} /$ $\mathrm{mL}$ at Week 3 .
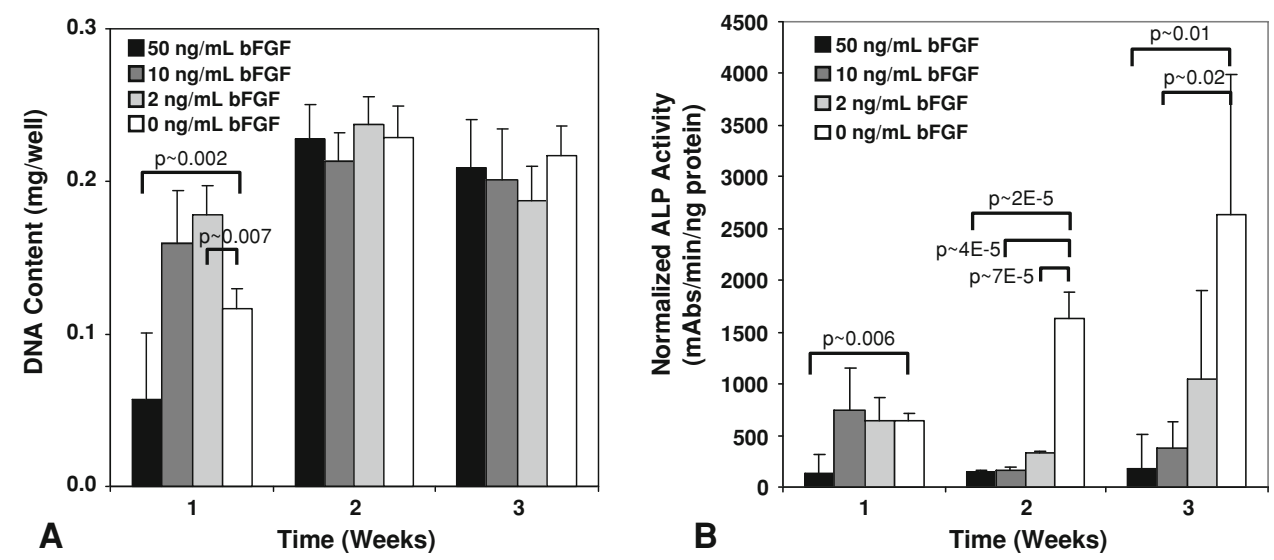

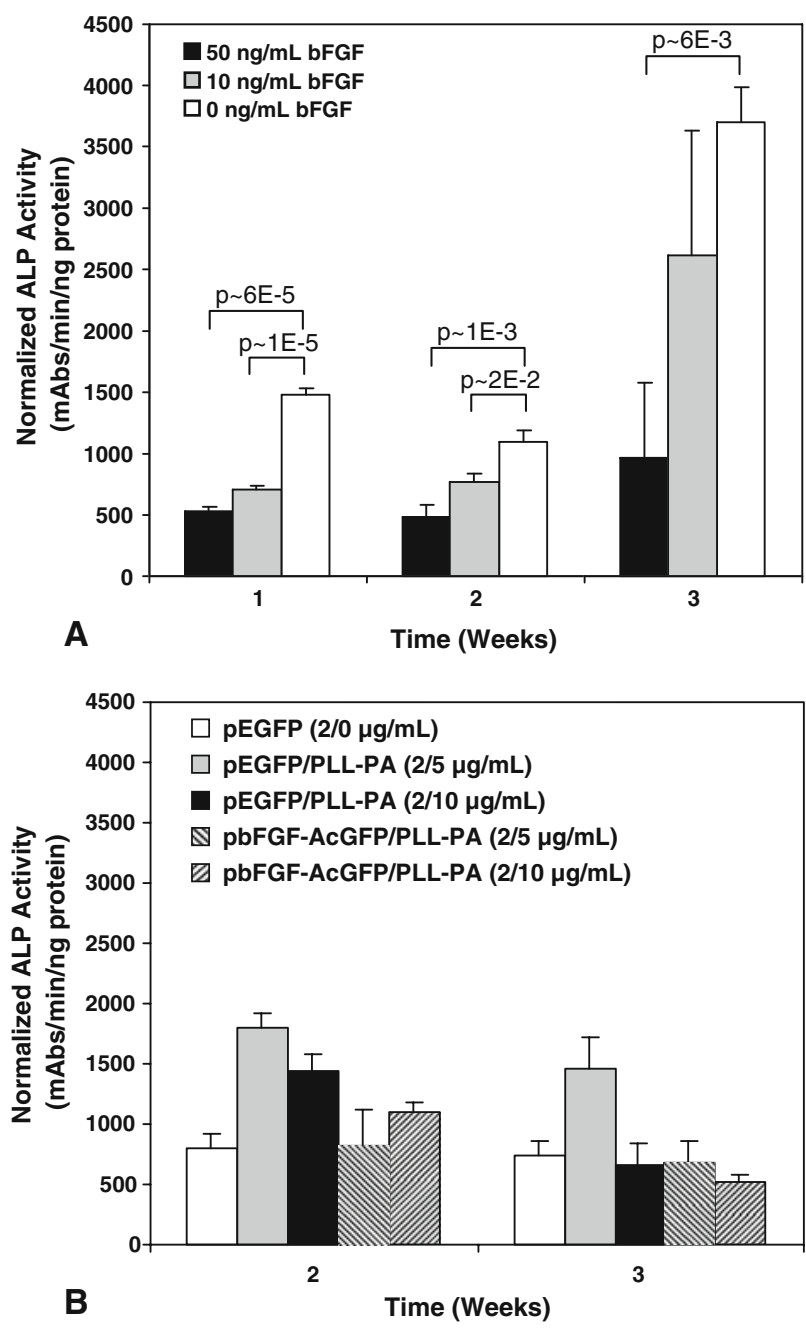

Fig. 4A-B (A) ALP activity of BMSC after 1, 2 and 3 weeks of bFGF treatment. Ten and $50 \mathrm{ng} / \mathrm{mL}$ bFGF gave a significant reduction of ALP activity after 1 and 2 weeks, but only $50 \mathrm{ng} / \mathrm{mL}$ bFGF gave a significant reduction of ALP activity after 3 weeks. (B) ALP activity of BMSC after 2 and 3 weeks of treatment with plasmid/ polymer complexes. Transfections with complexes were carried out for 24 hours, after which the medium was changed to OM for the rest of the incubation period. This experiment was independently repeated two times more with similar results.

number of cells in the no treatment and plasmid alone groups were $\sim 2.5$-fold higher than the high dose of PLL-PA and both doses of PEI complexes, indicating an impediment to cell growth even at these low polymer concentrations (Fig. 6A). We observed no difference in bFGF secretion on Day 5 (not shown) and Day 10 (Fig. 6B) among the study groups. When the amount of bFGF secretion was normalized with the number of cells (Fig. 6C), BMSC treated with 1.3/4.2 pFGF2-IRES-AcGFP/PLL-PA and $1.3 / 1.6 \mu \mathrm{g} / \mathrm{mL}$ pFGF2-IRES-AcGFP/PEI complexes had the highest bFGF synthesis rate $\left(\sim 3 \mathrm{ng} \mathrm{bFGF} / 10^{6}\right.$ cells over 10 days; $\mathrm{p} \sim 0.02$ compared to control, based on $\mathrm{t}$ test with unequal variances).
Unlike BMSC, the 293T cells treated with pFGF2IRES-AcGFP complexes readily gave bFGF in the supernatants (Fig. 7). Lipofectamine ${ }^{\mathrm{TM}} 2000$ appeared more effective in delivering the bFGF plasmid at both 2.5 and $5 \mu \mathrm{g} / \mathrm{mL}$ concentrations $(\mathrm{p} \sim 4 \mathrm{E}-5$ at $2.5 \mu \mathrm{g} / \mathrm{mL}$ and $\mathrm{p} \sim 1 \mathrm{E}-5$ at $5 \mu \mathrm{g} / \mathrm{mL}$ ). The bFGF concentration reached 10 to $16 \mathrm{ng} / \mathrm{mL}$ in the treatment groups, $\sim 150$-fold higher than the concentrations obtained with the BMSC transfections. We observed no obvious toxicity in any of the treatment on 293T cells (not shown), indicating relatively robust nature of these cells.

\section{Discussion}

In this study, the feasibility of modifying BMSC for bFGF secretion was investigated by delivering the growth factor gene by nonviral methods. BMSC modified in this way could serve as the basis of an osteogenesis therapy once transplanted into a host, since bFGF is capable of stimulating osteogenic differentiation of BMSC in vitro [22] and deposition of new bone after local and systemic administration. We therefore explored the effect of bFGF on BMSC after delivering the bFGF either as a recombinant protein or as a gene expression vector in the form of a plasmid. The bFGF effect on BMSC (ie, a reduction in ALP activity) was determined and compared between the protein and gene delivery approaches. The bFGF secretion was subsequently quantitated from the BMSC and compared to secretion from the easily modifiable 293T cells.

We note several assumptions and limitations. First we assumed the presence of bFGF in culture supernatants is a direct measure of bFGF expression. This might reflect an underestimate of bFGF expression since the protein may adsorb to extracellular matrix [24] under culture conditions. Second, we assumed the secreted protein was bioactive reminiscent of the plasmid-driven bFGF production in chondrocytes [29], although the secreted protein bioactivity was not directly assessed in this study. Third, a critical issue with nonviral carriers is the inherent cytotoxicity of the plasmid/polymer complexes, which was evident with the BMSC cells (Fig. 6). The highly robust nature of $293 \mathrm{~T}$ cells as well as their rapid proliferation might have overcome the cytotoxic treatment effects. Nevertheless the cytotoxic effects of the carriers must be minimized for effective gene expression. Increasing the hydrophilicity of polymeric carriers (eg, by polyethyleneglycol substitution, [5]) or incorporating biomimetic peptide motif (eg, nuclear targeting sequences, [4]) might be undertaken for this end. bFGF might be a unique growth factor in this perspective, since it may facilitate rapid recovery of the cells after polyplex treatment due to the stimulatory effects of the growth factor on 
Fig. 5 bFGF synthesis by BMSC after 6 days of transfection in 6well plates with pFGF2-IRESAcGFP/PLL-PA complexes is shown. The concentration of bFGF in cell supernatants was investigated by the ELISA. The cells treated with the pFGF2IRES-AcGFP/PLL-PA $\quad(2 / 5 \mu \mathrm{g} /$ $\mathrm{mL}$ ) complexes gave significant bFGF secretion into the culture medium.

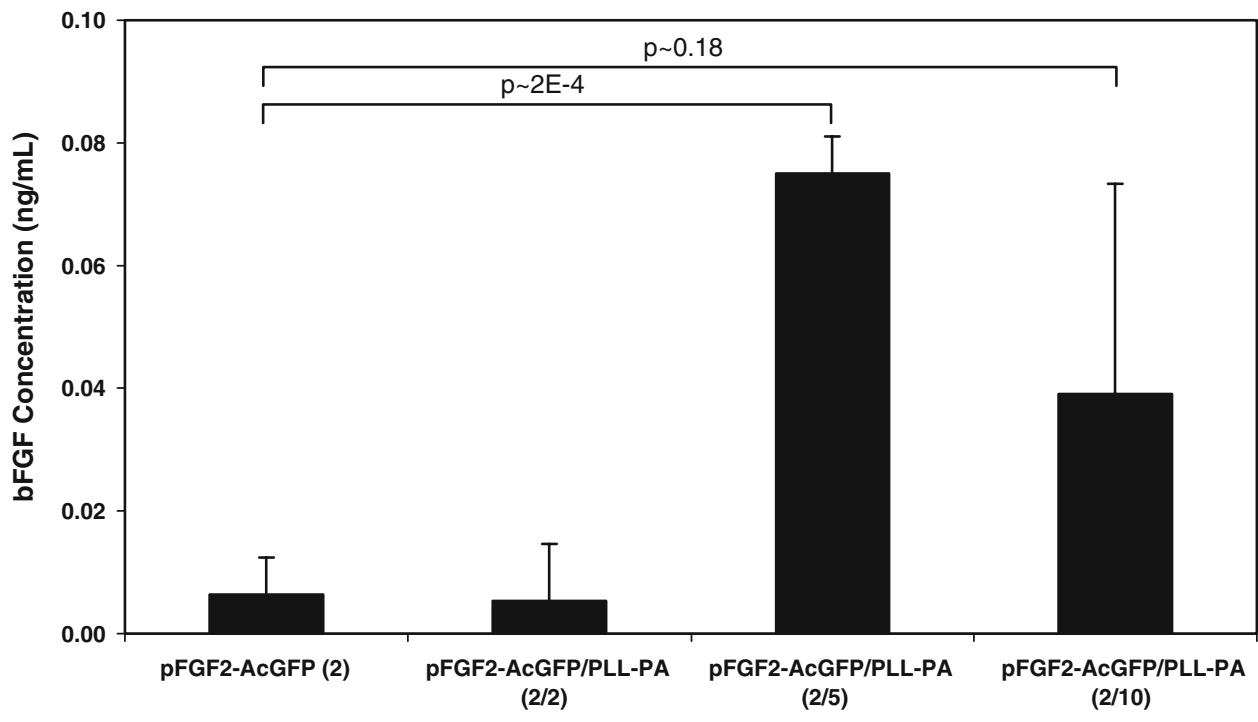

cell proliferation. For example, an increase in number of viable chondrocytes was reported when the cells were transfected with a bFGF-expression plasmid and a nonliposomal lipid formulation FuGENE ${ }^{\mathrm{TM}} 6$ [18], presumably due to growth stimulatory effects of the expressed protein.

A critical issue for bFGF-based therapy is the amount of protein needed for a therapeutic effect in situ. As a part of nonviral bFGF delivery efforts, Kaul et al. induced bFGF production in chondrocytes by using FuGENE ${ }^{\mathrm{TM}} 6$ as the carrier [18]. A maximum of $47.4 \mathrm{ng} \mathrm{bFGF} / 10^{7}$ viable cells was secreted 2 days after transfection $\left(\sim 2.4 \mathrm{ng} / 10^{6}\right.$ cells/ day), and this amount decreased to $2 \mathrm{ng} / 10^{7}$ viable cells on Day 29. The bFGF secretion was sufficient for repair of cartilage defects via stimulation of chondrogenesis. In another study, Haastert et al. transfected Schwann cells with Metafectene ${ }^{\mathrm{TM}}$ and implanted them into sciatic nerves of rats in silicon tubes [12]. Control (ie, unmodified) cells explanted from the host after 1 week led to bFGF concentration of $\sim 0.56 \mathrm{ng} / \mu \mathrm{L}$ in culture, whereas modified cells had built up a concentration of 1 to $2 \mathrm{ng} / \mu \mathrm{L} \mathrm{bFGF}$. Despite the small difference (two- to four-fold), bFGF gene delivery led to changes in myelination of regenerating axons. These results suggest that a relatively small augmentation of bFGF might be sufficient for a therapeutic effect.

The bFGF protein treatment of BMSC resulted in a reproducible down-regulation of ALP activity in culture, similar to our previous observations [31]. Optimum conditions for osteogenic differentiation of BMSC were adopted in this study to prevent detrimental effects of the osteogenic supplement $\beta$-GP on colony proliferation [6, 28] and viability [23]. The effect of bFGF on ALP activity has been variable in the literature, some studies noted an increase in all osteogenic markers in BMSC cultures [15], whereas others reported some markers to be influenced by the bFGF but not others, including the ALP activity [9, 21]. The timing of bFGF exposure was critical for its effect on ALP activity [26]; bFGF was stimulatory on ALP activity during early maturation of BMSC cells, but displayed no effect once the cells reached maturation at later stages in culture. The composition of the culture medium was a factor in influencing the bFGF effect on ALP activity [30], so that it is not surprising to have such variable results from independent labs. Our culture conditions typically resulted in lowering of ALP activity and, under these conditions, there was no evidence for a down-regulation of specific ALP activity after gene delivery. We considered the most likely reason for this observation to be the relatively small amount of bFGF secretion from the modified cells.

Direct determination of bFGF concentration in the culture medium indicated small but significant amounts of bFGF secretion into the culture medium by the FGF2IRES-AcGFP delivered BMSC. The intracellular levels of bFGF were determined in parallel studies in order to explore the possibility of a hurdle to bFGF secretion by the BMSC. However, there was no evidence of intracellular accumulation of the protein as well (not shown). The protein concentrations sustained in culture medium by bFGF gene expression $(\sim 0.1 \mathrm{ng} / \mathrm{mL})$ was significantly lower than the concentrations required for a significant reduction in ALP activity in short-time studies $(\sim 10 \mathrm{ng} /$ $\mathrm{mL})$. This is the likely reason for no changes in ALP activity. A previous study from the authors' lab conducted head-to-head comparison of the nonviral transfection of BMSC and 293T cells [16]. Based on GFP expression, it was clear that BMSC displayed a relatively low (1\%-5\%) transfection efficiency with PEI, whereas more than $90 \%$ transfection was obtained in 293T cells under identical culture/transfection conditions. The exact reason(s) for this 
Fig. 6A-C (A) Day 10 cell counts for BMSC treated with pFGF2-IRES-AcGFP/PLL-PA and pFGF2-IRES-AcGFP/PEI complexes. Cells treated with PLLPA and PEI complexes all gave significantly lower cell numbers as compared to untreated cells. (B) bFGF concentration in the supernatant of treated cells after 10 days. BMSC treated with both PLL-PA complexes and 1.3/ $1.6 \mu \mathrm{g} / \mathrm{mL}$ pFGF2-IRES-AcGFP/ PEI complexes gave higher bFGF concentration in medium but the differences were not different from untreated control. (C) The bFGF secretion normalized with the cell numbers. All groups with complex treatments gave significant level of specific bFGF secretion ( $\mathrm{p}$ was at least $<0.04$ ).
Fig. 7 bFGF concentration in the supernatant of $293 \mathrm{~T}$ cells transfected with the bFGF expression vector $\mathrm{pFGF} 2$-IRES-AcGFP. The delivery systems used for plasmid complexation were PEI and Lipofectamine $^{\mathrm{TM}} 2000$ at 2.5 and $5 \mu \mathrm{g} / \mathrm{mL}$. All four study groups treated with plasmid complexes gave higher amount of bFGF secretion into the culture supernatant as compared to untreated (control) cells.
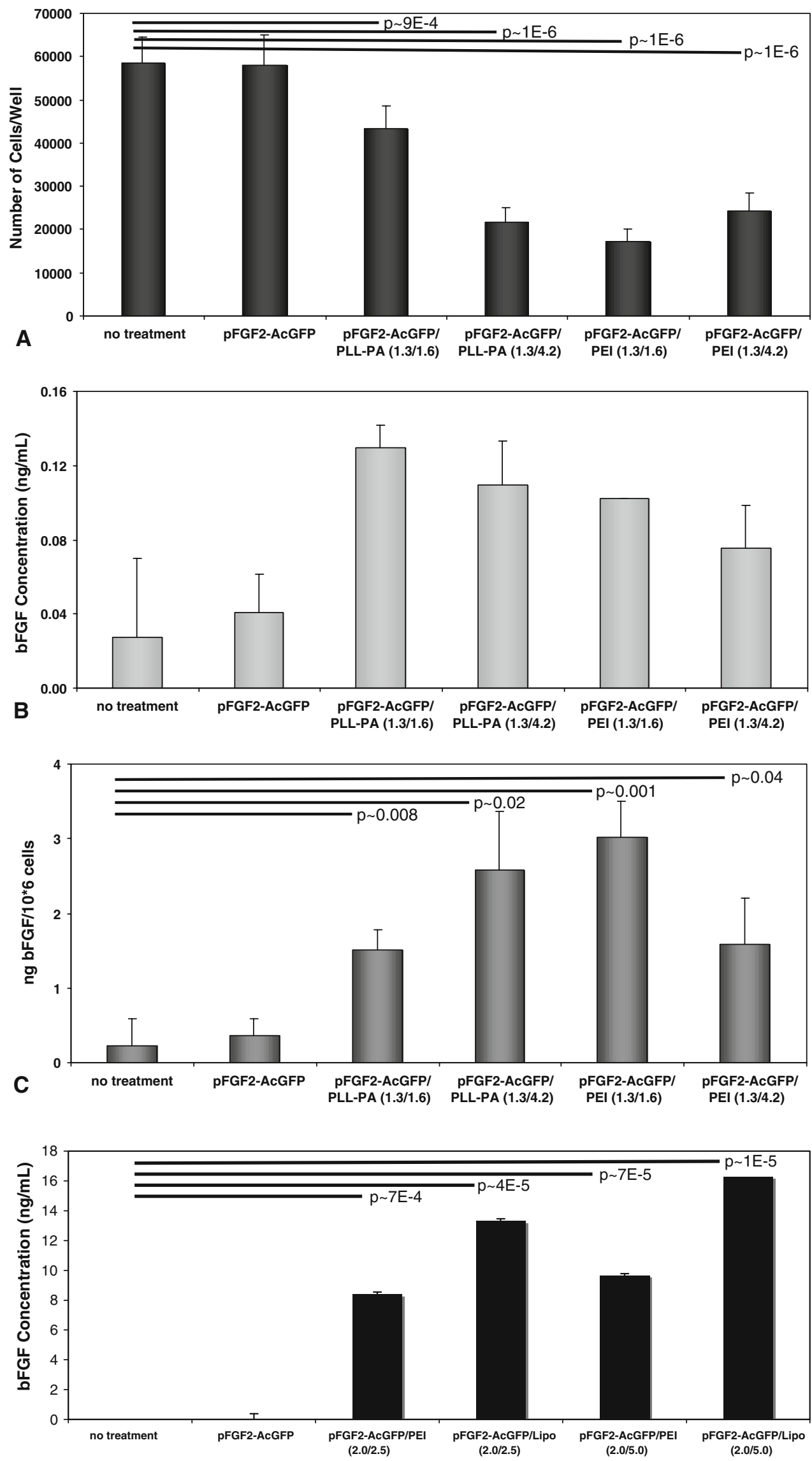
difference between the two cell types is (are) not known. Given this difference, we explored bFGF expression in the latter cells and, in line with previous studies, we obtained $\sim 150$-fold higher bFGF secretion into the culture medium $(\sim 15 \mathrm{ng} / \mathrm{mL}$ bFGF with $293 \mathrm{~T}$ cells versus $<0.1 \mathrm{ng} / \mathrm{mL}$ with BMSC cells). Although AcGFP gene was also present in the delivered plasmid, its expression was not clearly demonstrated in BMSC in this study (not shown), again indicating low transfection efficiency of these cells. It will be very beneficial to reveal the underlying reasons for the low transfection efficiency of BMSC and, conversely, the high transfection efficiency of the 293T cells.

Although we wanted to compare the bFGF secretion obtained in BMSC in this study with other studies exploring nonvirally modified BMSC [33], no such data were reported in the literature. Only indirect beneficial effects of bFGF expression on osteogenic marker expression were reported. Absolute amounts of bFGF secretion were reported with different cell types. The amounts of bFGF secreted after transduction by Sca- $1^{+}$hematopoietic cells with a Moloney leukemia virus was $\sim 18 \mathrm{ng} / 10^{6}$ cells $\left(\sim 6 \mathrm{ng} / 10^{6}\right.$ cells/day) for the unmodified bFGF plasmid and $320 \mathrm{ng} / 10^{6}$ cells $\left(\sim 107 \mathrm{ng} / 10^{6}\right.$ cells/day) for a bFGF plasmid modified with a BMP promoter to increase its secretion [14]. The bFGF transfected Sca- $1^{+}$hematopoietic cells were able to stimulate systemic bone formation and the authors reported a greater than 100-fold elevation in serum bFGF level, with substantial endosteal bone formation [14]. BMSC in this study secreted much lower amounts of bFGF; $\sim 3 \mathrm{ng}$ bFGF $/ 10^{6}$ cells over 10 days $\left(0.3 \mathrm{ng} / 10^{6}\right.$ cells/day). This is 20 - to 300 -fold lower than the rate for Sca- $1^{+}$hematopoietic cells. Other studies using viral carriers for bFGF delivery reported varying amounts of $\mathrm{bFGF}$ production; 15 or $7 \mathrm{ng} \mathrm{bFGF} / 10^{6}$ cells/day was produced by 293 packaging cells or $\mathrm{C} 2$ mouse myoblast cells, respectively, when transfected with an adenoviral carrier [10]. Another adenoviral carrier was used to transfect human umbilical vein endothelial cells and retinal pigment epithelial cells, yielding a maximum of $80 \mathrm{ng}$ $\mathrm{bFGF} / 10^{6}$ cells/day and $35 \mathrm{ng} \mathrm{bFGF} / 10^{6}$ cells/day, respectively [3]. Such rates are similar to bFGF secretion rate obtained with $293 \mathrm{~T}$ cells in our hands (note that cell counts were not taken with $293 \mathrm{~T}$ cells, but given that the bFGF concentration in medium was $\sim 150$-fold higher than the concentration in BMSC, we estimate the secretion rate to be $\sim 30 \mathrm{ng} / 10^{6}$ cells/day). It is clear that nonviral gene delivery can achieve bFGF secretion at a rate similar to viral systems in immortal (ie, easy-to-transfect) cells, but their efficacy must be improved for primary cells.

Our data suggest that bFGF was successfully synthesized in vitro upon modification of BMSC with pFGF2IRES-AcGFP/polymer complexes. The extent of bFGF secretion, however, was lower than other delivery systems and cells reported in the literature. It remains to be seen if BMSC genetically modified with bFGF ex vivo can produce sufficient bFGF for local stimulation of osteoprogenitor cells in vivo. Efforts to increase bFGF expression in BMSC will be beneficial for advancing bFGF gene therapy into the clinical realm.

Acknowledgments We thank Ms. Vanessa Incani for the synthesis and characterization of PLL-PA used in this study.

\section{References}

1. Abbasi M, Uludag H, Hsu C, Incani V, Jeffery A. Further investigation of lipid-substituted poly(L-Lysine) polymers for transfection of human CRL fibroblasts. Biomacromolecules. 2008;9:1618-1630.

2. Ai-Aql ZS, Alagl AS, Graves DT, Gerstenfeld LC, Einhorn TA. Molecular mechanisms controlling bone formation during fracture healing and distraction osteogenesis. J Dent Res. 2008;87:107-118.

3. Akimoto M, Miyatake S, Kogishi J, Hangai M, Okazaki K, Takahashi JC, Saiki M, Iwaki M, Honda Y. Adenovirally expressed basic fibroblast growth factor rescues photoreceptor cells in RCS rats. Invest Ophthalmol Vis Sci. 1999;40:273-279.

4. Cartier R, Reszka R. Utilization of synthetic peptides containing nuclear localization signals for nonviral gene transfer systems. Gene Ther. 2002;9:157-167.

5. Choi YH, Liu F, Kim J-S, Choi YK, Park JS, Kim SW. Polyethylene glycol-grafted poly-l-lysine as polymeric gene carrier. J Control Release. 1998;54:39-48.

6. Dobson K, Reading L, Scutt A. A cost-effective method for the automatic quantitative analysis of fibroblastic colony-forming units. Calcif Tissue Int. 1999;65:166-172.

7. Erlebacher A, Filvaroff EH, Gitelman SE, Derynck R. Toward a molecular understanding of skeletal development. Cell. 1995;80:371-378.

8. Farrell LL, Pepin J, Kucharski C, Lin X, Xu Z, Uludag H. A comparison of the effectiveness of cationic polymers poly-Llysine (PLL) and polyethyleneimine (PEI) for non-viral delivery of plasmid DNA to bone marrow stromal cells. Eur J Pharm Biopharm. 2007;65:388-397.

9. Frank O, Heim M, Jakob M, Barbero A, Schafer D, Bendik I, Dick W, Heberer M, Martin I. Real-time quantitative RT-PCR analysis of human bone marrow stromal cells during osteogenic differentiation in vitro. J. Cell. Biochem. 2002; 85:737-746.

10. Garcia-Martinez C, Opolon P, Trochon V, Chianale C, Musset K, Lu H, Abitbol M, Perricaudet M, Ragot T. Angiogenesis induced in muscle by a recombinant adenovirus expressing functional isoforms of basic fibroblast growth factor. Gene Ther. 1999;6:1210-1221.

11. Guo X, Zheng Q, Kulbatski I, Yuan Q, Yang S, Shao Z, Wang H, Xiao B, Pan Z, Tang S. Bone regeneration with active angiogenesis by basic fibroblast growth factor gene transfected mesenchymal stem cells seeded on porous b-TCP ceramic scaffolds. Biomed Mater. 2006;1:93-99.

12. Haastert K, Lipokatic' E, Fischer M, Timmer M, Grothe C. Differentially promoted peripheral nerve regeneration by grafted Schwann cells over-expressing different FGF-2 isoforms. $\mathrm{Neu}$ robiol Dis. 2006;21:138-153.

13. Hacein-Bey-Abina S, Von Kalle C, Schmidt M, McCormack MP, Wulffraat N, Leboulch P, Lim A, Osborne CS, Pawliuk R, Morillon E, Sorensen R, Forster A, Fraser P, Cohen JI, de Saint 
Basile G, Alexander I, Wintergerst U, Frebourg T, Aurias A, Stoppa-Lyonnet D, Romana S, Radford-Weiss I, Gross F, Valensi F, Delabesse E, Macintyre E, Sigaux F, Soulier J, Leiva LE, Wissler M, Prinz C, Rabbitts TH, Le Deist F, Fischer A, Cavazzana-Calvo M. LMO2-associated clonal T cell proliferation in two patients after gene therapy for SCID-X1. Science. 2003;302:415-419.

14. Hall SL, Lau KH, Chen ST, Wergedal JE, Srivastava A, Klamut $\mathrm{H}$, Sheng MH, Gridley DS, Mohan S, Baylink DJ. Sca-1 + hematopoietic cell-based gene therapy with a modified FGF-2 increased endosteal/trabecular bone formation in mice. Mol Ther. 2007;15:1881-1889.

15. Hori Y, Inoue S, Hirano Y, Tabata Y. Effect of culture substrates and fibroblast growth factor addition on the proliferation and differentiation of rat bone marrow stromal cells. Tissue Eng. 2004;10:995-1005.

16. Hsu CY, Uludag H. Effect of size and topology of DNA molecules on intracellular delivery with non-viral gene carriers. $B M C$ Biotechnol. 2008;8:23.

17. Hughes FJ, Turner W, Belibasakis G, Martuscelli G. Effects of growth factors and cytokines on osteoblast differentiation. Periodontol 2000. 2006;41:48-72.

18. Kaul G, Cucchiarini M, Arntzen D, Zurakowski D, Menger MD, Kohn D, Trippel SB, Madry H. Local stimulation of articular cartilage repair by transplantation of encapsulated chondrocytes overexpressing human fibroblast growth factor 2 (FGF-2) in vivo. J Gene Med. 2006;8:100-111.

19. Kawaguchi H, Nakamura K, Tabata Y, Ikada Y, Aoyama I, Anzai J, Nakamura T, Hiyama Y, Tamura M. Acceleration of fracture healing in nonhuman primates by fibroblast growth factor-2. J Clin Endocrinol Metab. 2001;86:875-880.

20. Kwan MD, Slater BJ, Wan DC, Longaker MT. Cell-based therapies for skeletal regenerative medicine. Hum Mol Genet. 2008;17(R1):R93-R98.

21. Locklin RM, Williamson MC, Beresford JN, Triffitt JT, Owen ME. In vitro effects of growth factors and dexamethasone on rat marrow stromal cells. Clin. Orthop. Relat. Res. 1995;313:27-35.

22. Martin I, Muraglia A, Campanile G, Cancedda R, Quarto R. Fibroblast growth factor-2 supports ex vivo expansion and maintenance of osteogenic precursors from human bone marrow. Endocrinology. 1997;138:4456-4462.

23. Meleti Z, Shapiro IM, Adams CS. Inorganic phosphate induces apoptosis of osteoblast-like cells in culture. Bone. 2000;27:359-366.
24. Miao HQ, Ishai-Michaeli R, Atzmon R, Peretz T, Vlodavsky I. Sulfate moieties in the subendothelial extracellular matrix are involved in basic fibroblast growth factor sequestration, dimerization, and stimulation of cell proliferation. J Biol. Chem. 1996; 271:4879-4886.

25. Nakamura K, Kurokawa T, Kawaguchi H, Kato T, Hanada K, Hiyama Y, Aoyama I, Nakamura T, Tamura M, Matsumoto T. Stimulation of endosteal bone formation by local intraosseous application of basic fibroblast growth factor in rats. Rev Rhum Engl Ed. 1997;64:101-105.

26. Nauman EA, Sakata T, Keaveny TM, Halloran BP, Bikle DD. bFGF administration lowers the phosphate threshold for mineralization in bone marrow stromal cells. Calcif. Tissue Int. 2003;73:147-152.

27. Raper SE, Chirmule N, Lee FS, Wivel NA, Bagg A, Gao GP, Wilson JM, Batshaw ML. Fatal systemic inflammatory response syndrome in a ornithine transcarbamylase deficient patient following adenoviral gene transfer. Mol Genet Metab. 2003;80:148158.

28. Rickard DJ, Kazhdan I, Leboy PS. Importance of 1,25-dihydroxyvitamin D3 and the nonadherent cells of marrow for osteoblast differentiation from rat marrow stromal cells. Bone. 1995;16:671-678.

29. Schmal H, Mehlhorn AT, Zwingmann J, Müller CA, Stark GB, Südkamp NP. Stimulation of chondrocytes in vitro by gene transfer with plasmids coding for epidermal growth factor (hEGF) and basic fibroblast growth factor (bFGF). Cytotherapy. 2005;7:292-300.

30. Still K, Reading L, Scutt A. Effects of phenol red on CFU-f differentiation and formation. Calcif. Tissue Int. 2003;73:173179.

31. Varkey M, Kucharski C, Haque T, Sebald W, Uludag H. In vitro osteogenic response of rat bone marrow cells to bFGF and BMP2 treatments. Clin Orthop Relat Res. 2006;443:113-123.

32. Yang C, Yang SH, Du JY, Li J, Xu WH, Xiong YF. Basic fibroblast growth factor gene transfection to enhance the repair of avascular necrosis of the femoral head. Chin Med Sci J. 2004;19:111-115.

33. Zheng Q, Guo X, Duan D, Liu Y, Wu Y. Gene-enhanced tissue engineering: Applications in osteoinduction using cultured mesenchymal stem cells transduced with the bFGF gene [in Chinese]. Sheng Wu Yi Xue Gong Cheng Xue Za Zhi. 2003;20: 443-446. 